\section{Partial peptides from rice defensin OsAFP1 exhibited antifungal activity against the rice blast pathogen Pyricularia oryzae}

\author{
Yoshiyuki Sagehashi, ${ }^{1, *}$ Hiroaki TAKakU ${ }^{2}$ \\ and Osamu Yatou ${ }^{3}$ \\ ${ }^{1}$ Hokkaido Agricultural Research Center, \\ National Agriculture and Food Research Organization, \\ Hitsujigaoka 1, Toyohira-ku, Sapporo, Hokkaido 062-8555, Japan \\ ${ }^{2}$ Department of Applied Life Sciences, \\ Niigata University of Pharmacy and Applied Life Sciences, \\ Higashijima 265-1, Niigata, Niigata 956-8603, Japan \\ ${ }^{3}$ Central Region Agricultural Research Center, \\ National Agriculture and Food Research Organization, \\ Inada 1-2-1, Joetsu, Niigata 943-0193, Japan
}

(Received July 18, 2017; Accepted September 20, 2017)

Rice blast caused by Pyricularia oryzae is one of the most devastating diseases worldwide. This study aimed to investigate the antifungal activity of rice defensin OsAFP1 and its partial peptides against $P$. oryzae. The partial peptides near the $\mathrm{N}$ - and C-terminal regions of OsAFP1 exhibited approximately the same antifungal activity as the entire protein against $P$. oryzae. These partial peptides have the potential to be used as fungicides. (C) Pesticide Science Society of Japan

Keywords: defensin, antifungal peptide, partial peptide, Oryza sativa, Pyricularia oryzae.

\section{Introduction}

Rice is one of the most important staple crops for more than half of the world's population. Rice blast caused by the fungal pathogen Pyricularia oryzae is the most devastating disease in riceproducing countries worldwide. Rice blast causes annual losses of $10-35 \%$ of the rice harvest. ${ }^{1)}$ The control of this disease has predominantly relied on breeding rice cultivars with durable resistance and applying agrochemicals. However, pathogens have been found to rapidly adapt to resistant cultivars in the field. Therefore, identifying novel antifungal compounds is necessary for developing new agrochemicals.

Plants are subjected to abiotic and biotic stresses, including pathogens. Several plants are known to produce antimicrobi-

\footnotetext{
* To whom correspondence should be addressed.

E-mail: sagehasi@affrc.go.jp

Published online October 31, 2017

(C) Pesticide Science Society of Japan
}

al peptides to defend themselves from pathogenic fungi. ${ }^{2)}$ One family of such peptides is plant defensin. ${ }^{3)}$ Plant defensins are small, basic, and cysteine-rich proteins of 45 to 54 amino acids that possess antifungal ${ }^{4)}$ and, in some cases, antibacterial activities. ${ }^{5)}$ Plant defensins share an identical three-dimensional folding pattern, which is stabilized by a tetradisulfide array, ${ }^{6)}$ forming a cysteine-stabilized $\alpha \beta$ backbone. ${ }^{7)}$

Over 40 genes encoding defensin-like proteins were predicted using DNA sequence analysis in the rice genome. ${ }^{8)}$ To clone defensin genes, which act as disease-resistant genes in rice plants, we searched for defensin-like protein genes in a rice genome database-The Rice Annotation Project Database (http://rapdb. dna.affrc.go.jp/index.html) - and selected four defensin genes from among those that shared the typical defensin sequences. ${ }^{9,10)}$ The defensin proteins encoded by these four defensin genes were expressed in Escherichia coli, and their antifungal activities against $P$. oryzae were investigated. While all four defensins exhibited antifungal activity, the OsAFP1 protein, which was encoded by AK121915 in the database, had the highest antifungal activity among the four defensins against $P$. oryzae; thus we performed further analysis on OsAFP1.

In a recent study on rice, two defensin genes, OsDEF7 and OsDEF8, were identified, and they were found to be upregulated in rice plants after infection with plant pathogens. ${ }^{11)}$ These defensin proteins exhibited antifungal and antimicrobial activity against rice pathogens. According to The Rice Annotation Project Database, the OsAFP1 cloned in this study and OsDEF7 ${ }^{11}$ ) are on the same site of chromosome II and have the same amino acid sequence, suggesting that both genes are the same.

OsAFP1 is a defensin consisting of 49 amino acids, including eight cysteine residues. It has a three-dimensional folding pattern, which is a characteristic form in plant defensins, stabilized by four disulfide bridges. Further, it was predicted to be an extracellular protein with a signal peptide consisting of 31 amino acids.

Although many studies have focused on defensins, the antimicrobial spectrum of rice defensins, including OsAFP1, has not been well analyzed. This study aimed to investigate the antifungal and antibacterial activities of OsAFP1 against rice pathogens, including $P$. oryzae.

In addition, we synthesized short partial peptides of OsAFP1 and assessed their antifungal activity against $P$. oryzae to explore the antifungal mechanism of the protein. These short peptides are also expected, due to their antifungal activities, to be potential novel fungicides with low production costs, as they would not require the complex synthesis and stabilization procedures essential for the full-length OsAFP1 protein. 


\section{Materials and Methods}

\section{OsAFP1 cloning}

Genomic DNA was extracted from the leaves of Oryza sativa $\mathrm{L}$. ssp. japonica 'Nipponbare' using an ISOPLANT Kit (Nippongene, Tokyo, Japan). The mature peptide DNA for OsAFP1 was cloned using a polymerase chain reaction (PCR) with the following primers: forward, 5' -AGGCACTGCCTGTCGCAGAGC-3', and reverse, $5^{\prime}$-CTAGCAGACCTTCTTGCAGAAG-3'. The amplified PCR products were resolved by agarose gel electrophoresis in a Tris-acetate-EDTA buffer and visualized by staining with $0.5 \mu \mathrm{g} / \mathrm{mL}$ ethidium bromide. The PCR amplicons were purified from $2.0 \%$ agarose gel slices by using SUPREC-EZ (Takara Bio, Shiga, Japan) and cloned into a pT7Blue vector (Novagen, Madison, WI, USA).

2. Construction, expression, and purification of recombinant OsAFP1

Mature OsAFP1 was amplified by PCR using the OsAFP1 DNA fragment cloned above as a template with oligonucleotide primers for OsAFP1 forward, 5'-CGCGGATCC-AGGCACTGC CTGTCGCAGAGC-3', and reverse, 5'-CCGGAATTC-CTA GCAGACCTTCTTGCAGAAG-3', that included a BamHI and EcoRI restriction site, respectively. The OsAFP1 expression vector, pGEX-6P-1/OsAFP1, was constructed by digesting the amplified mature region of OsAFP1 using BamHI and EcoRI and then cloning into the BamHI-EcoRI site of the pGEX-6P-1 glutathione-S-transferase (GST)-fusion expression vector (GE Healthcare, Piscataway, NJ, USA).

E. coli Rosetta-gami B (DE3) pLysS cells (Novagen, Madison, WI, USA) harboring pGEX-6P-1/OsAFP1 were grown in a modified Davis medium containing, per liter, $7 \mathrm{~g}$ of $\mathrm{K}_{2} \mathrm{HPO}_{4}, 2 \mathrm{~g}$ of $\mathrm{KH}_{2} \mathrm{PO}_{4}, 0.2 \mathrm{~g}$ of $\mathrm{MgSO}_{4}-7 \mathrm{H}_{2} \mathrm{O}, 0.5 \mathrm{~g}$ of $\left(\mathrm{NH}_{4}\right)_{2} \mathrm{SO}_{4}, 83 \mathrm{~g}$ of yeast extract, $30 \mathrm{~g}$ of glucose, and $100 \mu \mathrm{g} / \mathrm{mL}$ ampicillin at $37^{\circ} \mathrm{C}$ to an $\mathrm{OD}_{600}$ of 0.6. The expression of the GST-fused OsAFP1 was induced by adding isopropyl- $\beta$-D(-)-thiogalactopyranoside to a final concentration of $1 \mathrm{mM}$. After the cells were cultured for $18 \mathrm{hr}$ at $23^{\circ} \mathrm{C}$, they were harvested and disrupted by the addition of Triton X-100 after freeze/thawing in $1 \times$ PBS. The total soluble fraction was separated by centrifugation and filtered using a $0.45 \mu \mathrm{m}$ syringe filter, and the supernatant was subjected to a 5-mL GSTrap FF column (GE Healthcare) for affinity purification. The mature form of OsAFP1 was released from the GSTfused OsAFP1 by digestion for $18 \mathrm{hr}$ at $4^{\circ} \mathrm{C}$ using PreScission Protease (GE Healthcare). The eluted fraction was further purified by cation-exchange chromatography using a 5-mL HiTrap CM FF column (GE Healthcare) equilibrated with $50 \mathrm{mM}$ MES ( $\mathrm{pH}$ 6.0). The eluted recombinant mature OsAFP1 was concentrated and substituted with ultra-pure water using a Microcon YM-3 spin column (Millipore, Billerica, MA, USA).

\section{Short partial peptide of OsAFP1}

The eight short partial peptides of OsAFP1 (Peptide-1: RHCLSQSHRF, Peptide-2: SHRFKGMCVS, Peptide-3:
VSSNNCANV, Peptide-4: SNNCANVCRTE, Peptide-5: RTESFPDGE, Peptide-6: FPDGECKSHG, Peptide-7: KSHGLERKCF, and Peptide-8: ERKCFCKKVC) were synthesized at a purity of more than 98\% (Hokkaido System Science, Sapporo, Japan).

\section{Assay of antimicrobial activity}

Pyricularia oryzae Guy11 was obtained from Dr. M. Nishimura (Headquarters, National Agriculture and Food Research Organization, NARO). Rhizoctonia solani MAFF 305003, Gibberella fujikuroi MAFF 235968, Burkholderia plantarii MAFF 301723, Burkholderia glumae MAFF 301094, and Acidovorax avenae ssp. avenae MAFF 106618 were obtained from the Genetic Resources Center, NARO.

Antifungal activity was measured using a method similar to that of Broekaert et al. ${ }^{12)}$ by using half-strength potato dextrose broth containing $2 \times 10^{4}$ fungal spores/mL or short hyphal fragments $/ \mathrm{mL}$. The antibacterial activity was measured using the modified method of antifungal activity measurement. ${ }^{12)}$ The bacterial cells $\left(2.0 \times 10^{7} / \mathrm{mL}\right)$ were inoculated into one-quarterstrength polypeptone medium containing, per liter, $2.5 \mathrm{~g}$ of polypeptone, $0.5 \mathrm{~g}$ of yeast extract, and $0.25 \mathrm{~g}$ of $\mathrm{MgSO}_{4}-7 \mathrm{H}_{2} \mathrm{O}$.

A peptide solution $(20 \mu \mathrm{L})$ sterilized by heating for $10 \mathrm{~min}$ at $90^{\circ} \mathrm{C}$ and the culture solution with fungus or bacteria $(80 \mu \mathrm{L})$ were successively added to a microplate well and incubated for $96 \mathrm{hr}$ at $25^{\circ} \mathrm{C}$. The absorption at $595 \mathrm{~nm}$ was observed continuously by using a microplate reader (safire ${ }^{2}$; TECAN, Männedorf, Switzerland) to measure microbial growth. The $\mathrm{IC}_{50}$ values (i.e., the concentration of antifungal protein required to inhibit $50 \%$ of fungal growth) were calculated from dose-response curves.

\section{Results and Discussion}

The mature peptide DNA of OsAFP1 was cloned using PCR. Sequence analysis of the PCR product indicated that the fragment contained $150 \mathrm{bp}$ of the mature peptide region of OsAFP1. OsAFP1 is predicted to have a triple-stranded $\beta$-sheet with an $\alpha$-helix motif and eight cysteins that form four structure-stabilizing disulfide bridges (Fig. 1). The existence of the four disulfide bridges in the OsAFP1 was deduced from MALDI-TOF MS analysis for the OsAFP1 protein and the reduced OsAFP1 protein. ${ }^{13)}$

The heterologous production of defensin has already been reported. ${ }^{14)}$ In this study, we used the same method involving a

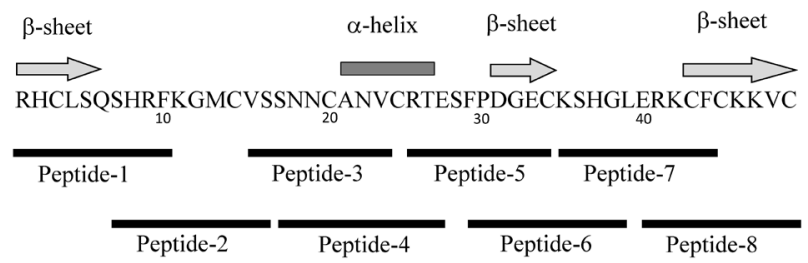

Fig. 1. The positions of partial peptides from OsAFP1. The arrows and a bar over the amino acid sequence indicate the predicted $\beta$-sheet and $\alpha$-helix, respectively. The black bars under the amino acid sequence indicate the positions of partial peptides of OsAFP1. 
Table 1. Antimicrobial spectrum of recombinant OsAFP1 against rice pathogens

\begin{tabular}{lc}
\hline \multicolumn{1}{c}{ Test rice pathogens } & $\left.\mathrm{IC}_{50}(\mu \mathrm{g} / \mathrm{mL})^{a}\right)$ \\
\hline Fungi & $0.99( \pm 0.05)$ \\
Pyricularia oryzae Guy11 & $1.48( \pm 0.25)$ \\
Rhizoctonia solani MAFF 305003 & $3.75( \pm 0.33)$ \\
Gibberella fujikuroi MAFF 235968 & \\
Bacteria & $>30$ \\
Burkholderia plantarii MAFF 301723 & $>30$ \\
Burkholderia glumae MAFF 301094 & $>30$ \\
Acidovorax avenae ssp. avenae MAFF 106618 & \\
\hline
\end{tabular}

a) Standard deviations of three replicates $(n=3)$ are indicated in the brackets.

pGEX-6P-1 vector and E. coli Rosetta-gami B (DE3) pLysS cells as in a previous study. ${ }^{14)}$ The pGEX-6P-1/OsAFP1 was transformed into the E. coli cells, enabling cytosolic disulfide bond formation of the expressed defensin proteins. In this study, OsAFP1 was expressed as a fusion protein with the GST tag, which might help maintain solubility in the expressed fusion protein. After the GST tag was removed, we successively obtained about $100 \mu \mathrm{g}$ of recombinant OsAFP1 per liter of culture of the transformed E. coli.

The mature recombinant OsAFP1 exhibited high antifungal activity against $P$. oryzae $\left(\mathrm{IC}_{50}=0.99 \mu \mathrm{g} / \mathrm{mL}\right), R$. solani $\left(\mathrm{IC}_{50}=\right.$ $1.48 \mu \mathrm{g} / \mathrm{mL})$, and G. fujikuroi $\left(\mathrm{IC}_{50}=3.75 \mu \mathrm{g} / \mathrm{mL}\right)$ but no antibacterial activity against $B$. plantarii, B. glumae, or A. avenae ssp. avenae. The $\mathrm{IC}_{50}$ for the bacteria might be over $30 \mu \mathrm{g} / \mathrm{mL}$. These results are summarized in Table 1. Tantong et al. reported that OsDEF7, which is the OsAFP1 in our study, inhibited the growth of rice pathogenic bacteria, Xanthomonas oryzae and Erwinia carotovora. ${ }^{11)}$ Therefore, further analysis would be required to confirm the species-specific antifungal activities of OsAFP1 against bacteria.

Transgenic rice carrying defensin genes from various plants exhibited resistance to pathogenic microbes. ${ }^{15-17)}$ The transgenic approach can be used to overexpress OsAFP1 in rice in order to confer protection against pathogens.
The use of OsAFP1 as a fungicide might not be a cost-effective approach, because the expression and purification of active OsAFP1 could be achieved only at high cost and low efficiency. Instead of using the entire OsAFP1 protein, we designed eight short partial peptides from the OsAFP1 sequence for the assessment of their antifungal activity against $P$. oryzae to create a new type of fungicide.

The peptide sequences and their antifungal activities are shown in Fig. 1 and Table 2. Peptides 1, 2, 7, and 8, which consist of 10 amino acid-long sequences near the $\mathrm{N}$ - and C-terminal regions of OsAFP1, exhibited antifungal activity against $P$. oryzae $\left(\mathrm{IC}_{50}=0.41-1.42 \mu \mathrm{g} / \mathrm{mL}\right)$. Peptide 3, 4, 5, and 6, which consist of 10 amino acid-long sequences in the central region of OsAFP1, exhibited no antifungal activity against $P$. oryzae. Among them, peptide 1 showed the highest antifungal activity, which was higher than that of OsAFP1. Peptides 2, 7, and 8 had approximately the same antifungal activity as OsAFP1. The stability of the three-dimensional structure in the full-length defensin protein is important for its antimicrobial activity. ${ }^{7)}$ However, in this study, partial peptides $1,2,7$, and 8 showed antifungal activity against $P$. oryzae. To our knowledge, this is the first study to show that some of the partial plant-defensin peptides possess approximately the same antifungal activity as the entire protein.

The partial peptides consisting of only 10 amino acids might exhibit more stable antifungal activity than the full-length OsAFP1 because the partial peptides are less susceptible to damage to the three-dimensional structure, which is stabilized by disulfide bridges, whereas this structure is essential to maintaining the antifungal activity of the full-length protein. In addition, unlike the full-length OsAFP1, they can be chemically synthesized in a more cost-effective manner. Therefore, these peptides that exhibit antifungal activity against $P$. oryzae have the potential to be used as fungicides.

The exact mechanisms of the antifungal activity of plant defensins are not yet known; however, some studies have suggested that plant defensins bind to a specific receptor in the fungal membrane. ${ }^{18,19)}$ According to this suggestion, OsAFP1 and the partial peptides might interact with unknown target molecules on the fungal membrane. The theoretical $\mathrm{pI}$ value of OsAFP1

Table 2. Antifungal activity of partial peptides of OsAFP1 against Pyricularia oryzae

\begin{tabular}{clcccc}
\hline Peptide variant & \multicolumn{1}{c}{ Sequence } & Molecular weight & pI & $\mathrm{IC}_{50}(\mu \mathrm{g} / \mathrm{mL})^{a)}$ & $\mathrm{IC}_{50}(\mu \mathrm{M})$ \\
\hline OsAFP1 & - & 5964 & 8.92 & $0.99( \pm 0.05)$ & 0.17 \\
Peptide 1 & RHCLSQSHRF & 1270 & 10.35 & $0.41( \pm 0.08)$ & 0.32 \\
Peptide 2 & SHRFKGMCVS & 1151 & 9.50 & $0.87( \pm 0.07)$ & 0.76 \\
Peptide 3 & VSSNNCANV & 907 & 5.49 & $>30$ & $>33.08$ \\
Peptide 4 & SNNCANVCRTE & 1210 & 5.71 & $>30$ & $>24.79$ \\
Peptide 5 & RTESFPDGE & 1037 & 4.14 & $>30$ & $>28.93$ \\
Peptide 6 & FPDGECKSHG & 1076 & 5.32 & 730 & $>27.88$ \\
Peptide 7 & KSHGLERKCF & 1204 & 9.31 & $0.84( \pm 0.71)$ & 0.70 \\
Peptide 8 & ERKCFCKKVC & 1244 & 9.11 & $1.42( \pm 0.30)$ & 1.14 \\
\hline
\end{tabular}

a) Standard deviations of three replicates $(n=3)$ are indicated in the brackets. 
was 8.92, and those of peptides $1,2,7$, and 8 were $10.35,9.50$, 9.31, and 9.11, respectively. In contrast, the theoretical pI values of peptides $3,4,5$, and 6 were 5.49, 5.71, 4.14, and 5.32, respectively. The peptides with high $\mathrm{pI}$ values could remain close to fungal membranes that are negatively charged; therefore, OsAFP1 and peptides $1,2,7$, and 8 are thought to exhibit antifungal activity against $P$. oryzae.

In defensins, although the three-dimensional molecular structure is important to retain the antimicrobial activity, the nature of this activity was largely electrostatic. ${ }^{20)}$ The molecular modification of the partial peptides of OsAFP1 with higher pI values might allow the enhancement of their antifungal activity against fungal rice pathogens. In the future, we intend to focus on elucidation of the wider antimicrobial spectrum of OsAFP1 and the partial peptides and activity enhancement of the partial peptides to use them as fungicides.

\section{Acknowledgements}

We thank Ms Yumi Ikeda for technical support and Dr. Marie Nishimura for kindly providing the P. oryzae strain. The P. oryzae Guyll strain was imported and used with special permission of the Ministry of Agriculture, Forestry and Fisheries of Japan.

\section{References}

1) M. C. Fisher, D. A. Henk, C. J. Briggs, J. S. Brownstein, L. C. Madoff, S. L. McCraw and S. J. Gurr: Nature 484, 186-194 (2012).

2) M. S. Castro and W. Fontes: Protein Pept. Lett. 12, 13-18 (2005).

3) O. Carvalho Ade and V. M. Gomes: Peptides 30, 1007-1020 (2009).

4) K. Vriens, B. P. Cammue and K. Thevissen: Molecules 19, 1228012303 (2014).

5) M. M. Rigano, A. Romanelli, A. Fulgione, N. Nocerino, N. D’Agostino, C. Avitabile, L. Frusciante, A. Barone, F. Capuano and R.
Capparelli: J. Pept. Sci. 18, 755-762 (2012).

6) W. F. Broekaert, F. R. Terras, B. P. Cammue and R. W. Osborn: Plant Physiol. 108, 1353-1358 (1995)

7) F. Fant, W. Vranken, W. Broekaert and F. Borremans: J. Mol. Biol. 279, 257-270 (1998).

8) K. A. Silverstein, W. A. Moskal Jr., H. C. Wo, B. A. Underwood, M. A. Graham, C. D. Town and K. A. VandenBosch: Plant J. 51, 262-280 (2007).

9) Y. Sagehashi, H. Takaku and O. Yatou: Abstr. 51st Annu. Meeting ICAAC, p181 (2011).

10) Y. Sagehashi and O. Yatou: Jpn. Kokai Tokkyo Koho JP2013-31431 (2013) (in Japanese).

11) S. Tantong, O. Pringsulaka, K. Weerawanich, A. Meeprasert, T. Rungrotmongkol, R. Sarnthima, S. Roytrakul and S. Sirikantaramas: Peptides 84, 7-16 (2016).

12) W. F. Broekaert, F. R. Terras, B. P. Cammue and J. Vanderleyden: FEMS Microbiol. Lett. 69, 55-59 (1990).

13) Y. Oguro, H. Yamazaki, M. Takagi and H. Takaku: Curr. Genet. 60, 89-97 (2014).

14) Y. Sagehashi, Y. Oguro, T. Tochihara, T. Oikawa, H. Tanaka, M. Kawata, M. Takagi, O. Yatou and H. Takaku: J. Pestic. Sci. 38, 33-38 (2013).

15) S. Jha, H. G. Tank, B. D. Prasad and B. B. Chattoo: Transgenic Res. 18, 59-69 (2009).

16) S. Jha and B. B. Chattoo: Transgenic Res. 19, 373-384 (2010).

17) H. Kanzaki, S. Nirasawa, H. Saitoh, M. Ito, M. Nishihara, R. Terauchi and I. Nakamura: Theor. Appl. Genet. 105, 809-814 (2002).

18) M. Wilmes, B. P. Cammue, H. G. Sahl and K. Thevissen: Nat. Prod. Rep. 28, 1350-1358 (2011).

19) I. Poon, A. A. Baxter, F. T. Lay, G. D. Mills, C. G. Adda, J. A. Payne, T. K. Phan, G. F. Ryan, J. A. White, P. K. Veneer, N. L. van der Weerden, M. A. Anderson, M. Kvansakul and M. D. Hulett: eLife 3, e01808 (2014).

20) D. M. Hoover, Z. Wu, K. Tucker, W. Lu and J. Lubkowski: Antimicrob. Agents Chemother. 47, 2804-2809 (2003). 